\title{
Effects of Renal Ischemic Postconditioning on Myocardial Ultrastructural Organization and Myocardial Expression of Bcl-2/Bax in Rabbits
}

\author{
Wen-zhong Zhang, Rong Li, Song Liu, Ji-dong Zhang, Xian-feng Ning, and Shang-lang Cai \\ Department of Cardiology, Affiliated Hospital of Qingdao University, Qingdao, Shandong 266003, China
}

Correspondence should be addressed to Ji-dong Zhang; zhangjidong@medmail.com.cn

Received 19 July 2016; Revised 10 November 2016; Accepted 17 November 2016

Academic Editor: Kazunori Uemura

\begin{abstract}
Copyright (C) 2016 Wen-zhong Zhang et al. This is an open access article distributed under the Creative Commons Attribution License, which permits unrestricted use, distribution, and reproduction in any medium, provided the original work is properly cited.
\end{abstract}

\begin{abstract}
We investigated the cardioprotective effect of renal ischemic postconditioning (RI-PostC) and its mechanisms in a rabbit model. Rabbits underwent $60 \mathrm{~min}$ of left anterior descending coronary artery occlusion (LADO) and $6 \mathrm{~h}$ of reperfusion. The ischemiareperfusion (IR) group underwent LADO and reperfusion only. In the RI-PostC group, the left renal artery underwent 3 cycles of occlusion for 30 seconds and release for 30 seconds, before the coronary artery was reperfused. In the RI-PostC + GF109203X group, the rabbits received $0.05 \mathrm{mg} / \mathrm{kg}$ GF109203X (protein kinase C inhibitor) intravenously for 10 min followed by RI-PostC. Light microscopy and electron microscopy demonstrated that the RI-PostC group showed less pronounced changes, a smaller infarct region, and less apoptosis than the other two groups. Bcl-2 and Bax protein expression did not differ between the IR and RI-PostC + GF109203X groups. However, in the RI-PostC group, Bcl-2 protein expression was significantly higher and Bax protein expression was significantly lower than in the other two groups $(P<0.05)$. Changes in heart rate and mean arterial pressure were also smaller in the RI-PostC group than in the other two groups. These results indicate that RI-PostC can ameliorate myocardial ischemia-reperfusion injury and increase the Bcl-2/Bax ratio through a mechanism involving protein kinase $\mathrm{C}$.
\end{abstract}

\section{Introduction}

Remote ischemic conditioning (RIC), where brief nonlethal ischemia is undertaken on a remote organ or tissue, is a technique that has the potential to protect the heart against ischemia-reperfusion injury $[1,2]$. In 1986, Murry et al. [3] brought attention to the phenomenon of ischemic preconditioning (IPC). Preconditioning can effectively reduce myocardial injury induced by ischemia-reperfusion and protect the myocardium. However, to be clinically useful, an IPC intervention must be made before myocardial ischemia occurs. Unfortunately, it is not possible to predict the timing of an ischemic episode in the clinical setting; therefore, IPC has very limited clinical use and so the concept of remote ischemic postconditioning has been explored. Ischemic postconditioning is a novel technique for reducing ischemiareperfusion injury that differs to IPC [4].

In recent years, domestic and foreign scholars have shown that ischemic postconditioning can exert a similar cardioprotective effect to IPC [5-8]. Repeated opening and closing of the coronary artery during reperfusion mitigated against ischemia-reperfusion damage and produced notable cardioprotection. Shliakhto et al. [8] found that ischemic postconditioning could significantly reduce the ventricular tachycardia evoked by continuous reperfusion in a rat isolated perfused heart model, presenting a new method to prevent reperfusion damage. It has also been reported that nontraumatic, bilateral, pelvic limb ischemic postconditioning can protect the ischemic-reperfused myocardium [911]. Ischemic postconditioning of other organs as a method for protecting the myocardium against ischemia-reperfusion injury is a new field of research [12-16].

There is now evidence that the protein kinase $\mathrm{C}$ (PKC) signaling pathway is involved in the process of ischemiareperfusion injury. The reactive oxygen species scavenger U83836E has been reported to protect against myocardial ischemia-reperfusion injury in rats by reducing oxidative stress and activating PKC [17]. Similarly, the cardioprotective 
effect of polydatin preconditioning has been attributed to activation of the PKC signaling pathway as well as antioxidative stress mechanisms [18]. Overexpression of diacylglycerol kinase in mouse heart was found to inhibit the activation of $\mathrm{PKC}$ and increase the infarct size and left ventricular systolic dysfunction associated with ischemia-reperfusion injury [19]. Interestingly, ischemic postconditioning has been reported to attenuate renal ischemia-reperfusion injury via PKC signaling, raising the possibility that PKC-dependent mechanisms may play a role in the cardioprotective effects of RIC [20].

This study aimed to investigate the effects of renal ischemic postconditioning (RI-PostC) on the ultrastructure and apoptosis-related gene expression of reperfused ischemic myocardium and determine the relevance of $\mathrm{PKC}$ signaling to any effects of RI-PostC.

\section{Materials and Methods}

2.1. Experimental Animals and Groupings. Thirty-six healthy New Zealand white rabbits (both genders, weighing 2.0$2.5 \mathrm{~kg}$ ) were obtained from the Animal Experiment Center of Zhengzhou University School of Medicine. The animals were kept separately in cages under normal conditions (temperature, $16-26^{\circ} \mathrm{C}$; relative humidity, 40-70\%; noise, $\leq 60 \mathrm{~dB}$; working illumination, 150-300 lx; and animal illumination, 100-200 lx). All rabbits were subjected to left anterior descending coronary artery occlusion (LADO) for $60 \mathrm{~min}$ followed by $6 \mathrm{~h}$ of reperfusion. The rabbits were then randomly allocated into one of three groups $(n=12$ per group). Rabbits in the IR group were subjected to ischemia and reperfusion without further intervention. Rabbits in the RI-PostC group were subjected to RI-PostC: after $60 \mathrm{~min}$ of LADO the left renal artery was occluded for 30 seconds and released for 30 seconds, and this was repeated for 3 cycles before the coronary artery was reperfused for $6 \mathrm{~h}$. In the RI-PostC + GF109203X group, the rabbits received $0.05 \mathrm{mg} / \mathrm{kg}$ of the protein kinase C antagonist GF109203X (Sigma Corporation) for $10 \mathrm{~min}$ (administered by auricular vein injection) followed by RI-PostC; the coronary artery was then reperfused for $6 \mathrm{~h}$ (Figure S1 in Supplementary Material available online at http://dx.doi.org/10.1155/2016/9349437). This study was approved by the Institutional Animals Ethics Committee of Qingdao University and was conducted in accordance with the Guidelines for the Care and Use of Laboratory Animals provided by the National Institutes of Health (NIH publication number 80-82).

2.2. Surgery. The animal model of ischemia and reperfusion was created using conventional methods [21]. The rabbit was anesthetized by injection of urethane $(1 \mathrm{~g} / \mathrm{kg})$ into the auricular vein and placed in the supine position. Electrocardiogram (ECG) leads were connected to the limbs and chest of the rabbit for recording of the 12-lead ECG. The hair at the neck was removed, the left common carotid artery was separated and intubated to connect with a pressure sensor, and the mean blood pressure (MAP) and heart rate (HR) were monitored with a BL-420E Data Acquisition Analysis System for Life Sciences (Taimeng, China). The ventilator rate was set at 45 beats/min. The chest hair was removed, and the skin was incised $0.5 \mathrm{~cm}$ to the left of the sternal midline to expose the third and fourth left ribs. Blunt separation of the intercostal muscles was performed, and 2 threads were used for ligation with small curved forceps. The third and fourth costal cartilages were resected along the ligature, after which the threads were retracted to expose the thoracic cavity. The adipose tissues were separated to expose the pericardium and beating heart. The pericardium was lifted at the middle, and a pair of ophthalmic scissors was used to cut the anterior part of the pericardium. The pericardium was sutured to the thoracic wall to fully expose the heart. The left auricle was gently lifted by a pair of hemostatic forceps to observe the path taken by the coronary artery. The left main coronary artery was used as the marker; a ligature was applied to the root of the anterior descending coronary artery through the surface layer of the myocardium with a small needle held in a holder, and the needle was pulled out at the tissue near the pulmonary conus. Another ligature was applied at about $0.5 \mathrm{~cm}$ below the first ligature. For the ligation, a plastic tube of diameter $0.2 \mathrm{~cm}$ was passed through the ligature, and then hemostatic forceps were used for clamping and ligation. After the left anterior descending branch had been double ligated for $1 \mathrm{~h}$, reperfusion was performed for $6 \mathrm{~h}$ under anesthesia with $3 \%$ pentobarbital at $1 \mathrm{ml} / \mathrm{kg}$ by injection in the ear-vein of the rabbit. ST segment elevation on the V1 lead of the ECG was considered as successful ligation.

For RI-PostC [22], a median abdominal incision was made, and the left renal artery was carefully identified and separated via a left retroperitoneal approach. 4-0 thread was positioned beneath the renal artery to help fix the artery; an artery clamp was used to occlude and release the renal artery. After the coronary artery had been ligated for $1 \mathrm{~h}$, the renal artery was subjected to 3 cycles of occlusion for 30 seconds followed by release for 30 seconds. Subsequently, reperfusion of the coronary artery was performed for $6 \mathrm{~h}$.

For all animals, samples of cardiac tissue were collected immediately after the $6 \mathrm{~h}$ period of cardiac reperfusion had ended.

2.3. Observation of Myocardial Cells by Light Microscopy. The infarct region was identified by nitroblue tetrazolium (NBT) staining, which is a commonly used method for this purpose [23]. As soon as the experiments had reached their endpoint (i.e., after $6 \mathrm{~h}$ of cardiac reperfusion), the heart was rapidly excised and washed with normal saline. The atria and right ventricle were removed and discarded, and the left ventricular tissue was stored at $-20^{\circ} \mathrm{C}$ until use. Cross-sectional slices of the left ventricle, with a thickness of $2 \mathrm{~mm}$, were obtained from the apex to the base, and the apical and basal slices were discarded. Slices located toward the cardiac apex were used for the analysis. The slices were incubated at $37^{\circ} \mathrm{C}$ for $20 \mathrm{~min}$ in phosphate-buffered saline (PBS) containing $0.5 \% \mathrm{NBT}$, and the slices were then washed with normal saline to remove residual dye. Using this technique, normal myocardium stained purple while necrotic myocardium stained graywhite. All slices were photographed with a digital camera with a fixed focus. An OPTO NVIDAS image analysis system (Germany) was used to measure the area of necrosis and calculate the area of necrosis as a percentage of the total area. 
A piece of tissue (about $5 \mathrm{~mm} \times 5 \mathrm{~mm} \times 2 \mathrm{~mm}$ ) from the center of each infarct region was stained using hematoxylin and eosin. Briefly, the tissue was removed, fixed with $10 \%$ formalin, and dehydrated with alcohol. The sample was then embedded in wax, sectioned, and dewaxed with xylene. Afterwards, the tissue sample was stained with hematoxylin, acid-washed until the background was transparent, stained again, and then rinsed. The section was sealed with neutral gum and observed microscopically. Morphological changes of the myocardial cells were then assessed.

\subsection{Observation of Myocardial Cells by Electron Microscopy.} Immediately after the period of reperfusion had ended, sections of ischemic and necrotic myocardial tissues were taken from all test animals and ultrathin sections were prepared [24]. Briefly, the tissues were removed and cut into $1 \mathrm{~mm}^{3}$ blocks and fixed for $4 \mathrm{~h}$ at $4^{\circ} \mathrm{C}$ with $2.5 \%$ glutaraldehyde. The samples were then rinsed 3 times with PBS and fixed for $3 \mathrm{~h}$ with $1 \%$ osmium tetroxide. The samples were rinsed an additional 3 times with PBS and then dehydrated by soaking in a mixture of acetone and Epon812 embedding medium $(1: 2)$. The tissues were then embedded with Epon 812 medium. Slices 50-100 $\mathrm{nm}$ in thickness were made using an ultramicrotome and dried and stained for 15 min with uranyl acetate. Afterwards the sections were washed thoroughly 3 times with distilled water, stained for $15 \mathrm{~min}$ with lead citrate, and then washed thoroughly 3 more times with distilled water. The samples were then examined by electron microscopy (model JEM-1200EX, JEOL Corporation, Japan).

2.5. Detection of Bcl-2 and Bax Protein Expression. A small amount of ischemic and necrotic myocardial tissue was removed from the test animals immediately after the end of the experiment (i.e., after $6 \mathrm{~h}$ of reperfusion) to assess the expression of the Bcl-2 and Bax gene products by Western blot analysis. The investigator performing these laboratory analyses was blinded to the grouping of the animals. Briefly, total protein content was extracted by the addition of $100-$ $200 \mu \mathrm{L}$ of lysis buffer (20 mM Tris [pH 7.5], $150 \mathrm{mM} \mathrm{NaCl}, 1 \%$ Triton $\mathrm{X}-100$, sodium pyrophosphate, $\beta$-glycerophosphate, EDTA, $\mathrm{Na}_{3} \mathrm{VO}_{4}$, and leupeptin) per $20 \mathrm{mg}$ sample. Samples were then centrifuged for $5 \mathrm{~min}$ at $12000 \mathrm{rpm}$ at $4^{\circ} \mathrm{C}$. Next, SDS-PAGE was performed using a $10 \%$ separation gel and a $5 \%$ stacking gel under constant high-voltage $(80 \mathrm{~V})$. To transfer to the stacking gel, the samples were subjected to constant current for about $3 \mathrm{~h}$ at room temperature (RT). Blocking solution was then added for $60 \mathrm{~min}$ at RT. Afterwards, diluted primary antibody (1:1000; Beyotime Corporation, China) was added and this was incubated overnight with shaking at RT. The gel was then washed 3 times $(10 \mathrm{~min}$ each) with Tris-buffered saline tween solution (TBST). A diluted secondary antibody (Beyotime Corporation, China), labeled with horseradish peroxidase (HRP), was added and incubated at RT for $1 \mathrm{~h}$ with shaking. Gels were then washed with TBST 3 times for $10 \mathrm{~min}$ each. 3,3'-Diaminobenzidine (DAB) color reagent was added for about $15 \mathrm{~min}$ and then washed off using double distilled water. Western blot images were analyzed with gel analysis software (Quantity One,
Bio-Rad Laboratories) and Origin75 software (OriginLab Corporation, USA).

2.6. Terminal Deoxynucleotidyl Transferase dUTP Nick End Labeling (TUNEL) Assay. Once the experiment had reached its endpoint (after reperfusion), a sample of necrotic myocardial tissue was fixed in $10 \%$ formaldehyde for $24 \mathrm{~h}$, after which paraffin embedding and sectioning were performed. The TUNEL method was used to measure cell apoptosis [25]. Cells with brown granules in the cell nucleus were considered to be apoptotic cells and were referred to as positive cells. Five visual fields under high magnification were chosen randomly to count the number of necrotic cells and calculate the apoptosis index (AI), defined as the percentage of positive cells among all cells: AI $=$ TUNEL positive cell count/total myocardial cell count $\times 100 \%$.

2.7. Statistical Analysis. Continuous variables are presented as mean \pm standard deviation (SD), and categorical variables are expressed as number and/or percentage. Comparisons between multiple groups were made using analysis of variance (ANOVA) with the least significant difference (LSD) post hoc test. SPSS 19.0 (SPSS Inc., USA) was used for statistical analysis. A value of $P<0.05$ was considered to indicate a statistically significant difference.

\section{Results}

In this study, four rabbits died of pneumothorax or cardiac death; we added an additional 4 rabbits to complete the experiment.

3.1. Observation of Myocardial Cells by Light Microscopy. In the IR group, there was myocardial interstitial edema, muscle fiber swelling, unclear cell boundaries, and disappearance of transverse striations. Additionally, granulocyte infiltration and a small quantity of red blood cell leakage were observed. In the RI-PostC group, there was mild edema, a regular arrangement of cardiomyocytes with clear cell boundaries, and no granulocyte infiltration or red blood cell leakage. In the RI-PostC + GF109203X group, myocardial interstitial edema, partial muscle fiber swelling, some cell lysis, unclear cell boundaries, an absence of transverse striations, granulocyte infiltration, and leakage of red blood cells were observed. These results are illustrated in Figure 1(a).

3.2. Infarct Area. Representative images showing NBT staining of infarct regions are presented in Figure 1(b). The infarct area (as a percentage of the total area) did not differ significantly between the IR and RI-PostC + GF109203X groups $(P>0.05$; Figure $1(\mathrm{c}))$. However, infarct area in the RI-PostC group was significantly smaller than that in the IR group and RI-PostC + GF109203X group (both $P<0.05$; Figure 1(c)).

3.3. Observation of Myocardial Cells by Electron Microscopy. In the IR group, myocardial cells were severely damaged and edematous. The mitochondria were swollen and extruding from the cells. The mitochondrial ridges were markedly 
IR

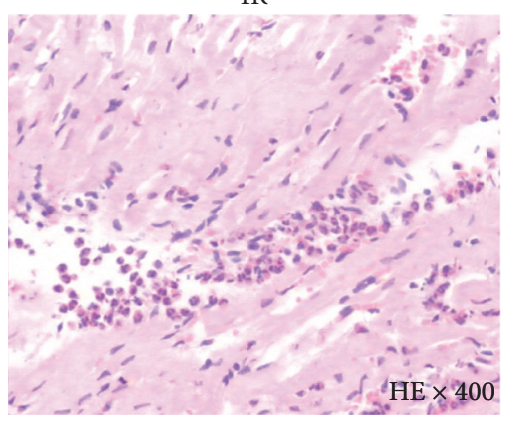

I/R group

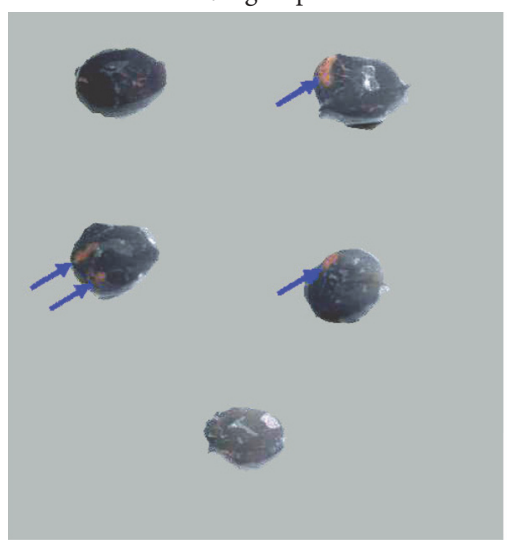

RI-PostC

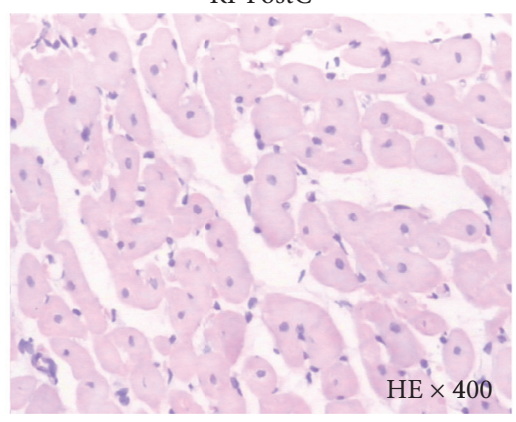

(a)

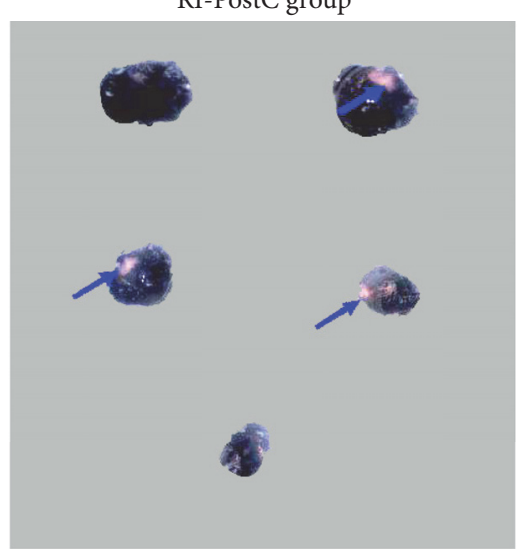

(b)

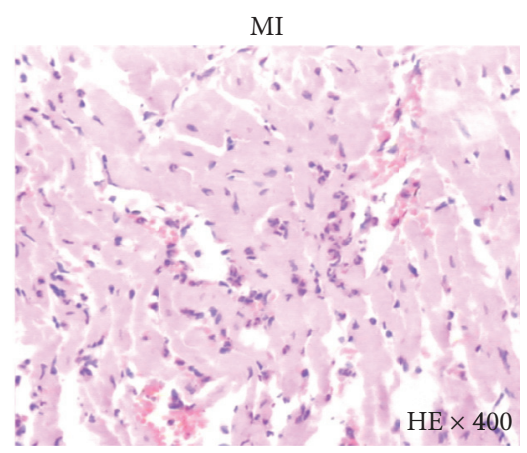

RI-PostC + GF109203X group

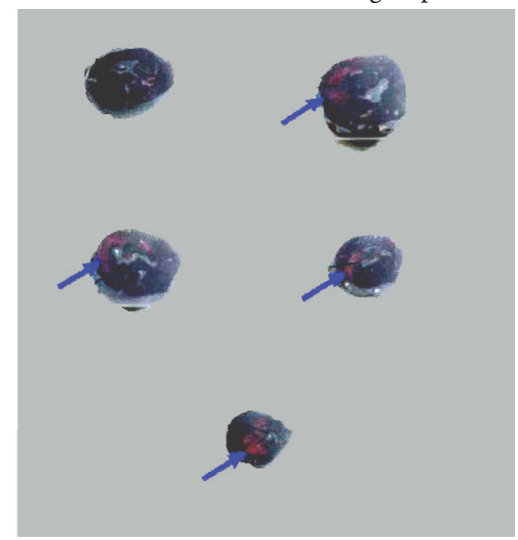

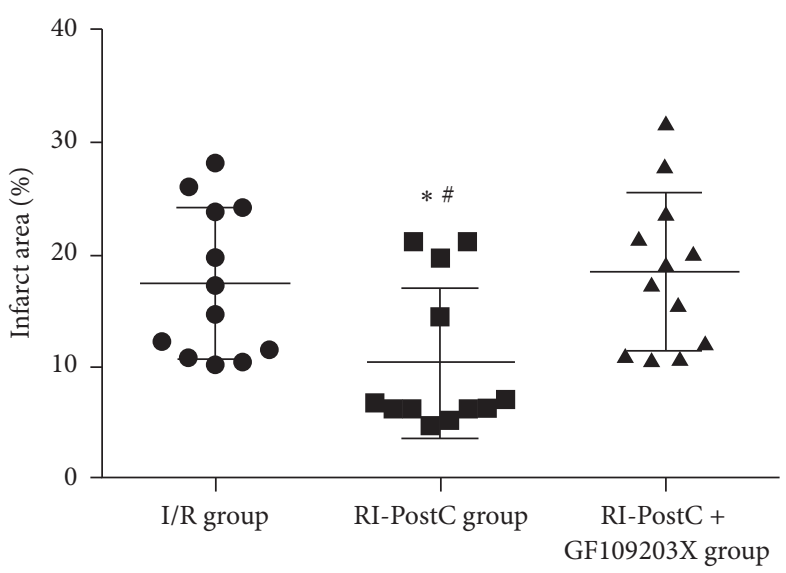

(c)

FIGURE 1: Comparison of cardiac histological changes and infarct area between experimental groups. The IR group underwent 60 min of left anterior descending coronary artery occlusion (LADO) and $6 \mathrm{~h}$ of reperfusion only. The RI-PostC group underwent 3 cycles of left renal artery occlusion for 30 seconds and release for 30 seconds before reperfusion. The RI-PostC + GF109203X group received $0.05 \mathrm{mg} / \mathrm{kg}$ GF109203X (protein kinase C inhibitor) intravenously for $10 \mathrm{~min}$ followed by RI-PostC. There were 12 rabbits in each group. (a) Light microscopy observations of HE-stained sections. IR group: granulocyte infiltration and a small quantity of red blood cell leakage were observed. RI-PostC group: mild myocardial interstitial edema was observed without granulocyte infiltration or red blood cell leakage. RI-PostC + GF109203X group: increased granulocyte numbers and leakage of red blood cells were observed. (b) Sections stained with NBT to identify regions of ischemia (arrows). (c) Comparison of infarct size between groups, calculated from experiments such as those shown in (b) $(n=12$ per group). Infarct area was calculated as the percentage of the total cell area. ${ }^{*} P<0.05$ compared with the IR group; ${ }^{\#} P<0.05$ compared with the RI-PostC + GF109203X group. 
TABLE 1: Changes in heart rate (beats/min) during ischemia-reperfusion.

\begin{tabular}{lcccccc}
\hline Group & $n$ & Before ischemia & $\begin{array}{c}\text { After 5 min of } \\
\text { ischemia }\end{array}$ & $\begin{array}{c}\text { After 1h of } \\
\text { ischemia }\end{array}$ & $\begin{array}{c}\text { After 3 h of } \\
\text { reperfusion }\end{array}$ & $\begin{array}{c}\text { After 6h of reperfusion } \\
\text { I/R group }\end{array}$ \\
RI-PostC group & 12 & $255 \pm 17$ & $224 \pm 15$ & $213 \pm 11$ & $146 \pm 9$ & $94 \pm 8$ \\
RI-PostC + GF109203X group & 12 & $253 \pm 16$ & $219 \pm 14$ & $209 \pm 10$ & $161 \pm 11^{* \#}$ & $121 \pm 6^{* \#}$ \\
\hline
\end{tabular}

${ }^{*} P<0.05$ compared with the IR group; ${ }^{\#} P<0.05$ compared with the RI-PostC + GF109203X group.

TABLE 2: Changes in MAP (MAP, mmHg) during ischemia-reperfusion.

\begin{tabular}{lcccccc}
\hline Group & $n$ & Before ischemia & $\begin{array}{c}\text { After 5 min of } \\
\text { ischemia }\end{array}$ & $\begin{array}{c}\text { After 1h of } \\
\text { ischemia }\end{array}$ & $\begin{array}{c}\text { After 3h of } \\
\text { reperfusion }\end{array}$ & $\begin{array}{c}\text { After 6h of reperfusion } \\
\text { I/R group }\end{array}$ \\
RI-PostC group & 12 & $121 \pm 11$ & $102 \pm 8$ & $90 \pm 7$ & $79 \pm 6$ & $71 \pm 7$ \\
RI-PostC + GF109203X group & 12 & $116 \pm 12$ & $101 \pm 10$ & $93 \pm 10$ & $88 \pm 10^{* \#}$ & $81 \pm 8^{* \#}$ \\
\hline
\end{tabular}

${ }^{*} P<0.05$ compared with the IR group; ${ }^{\#} P<0.05$ compared with the RI-PostC + GF109203X group.

less prominent, the electron density was decreased in the ground substance, the dense granules had reduced or even disappeared with vacuole formation, and the sarcolemma was damaged to varying degrees. Following membrane breakage or defects, the myofibrils became fuzzy, some $\mathrm{Z}$ lines were not clearly visible, nuclear swelling occurred, heterochromatin increased and condensed, and the nuclei became irregular and sometimes fragmented. In the RI-PostC group, there were less marked ultrastructural changes, with only a small degree of myocardial cell edema, slight swelling of the mitochondria, vacuolar degeneration, and partial disappearance of the mitochondrial ridges; the myofibrils were arranged regularly and in parallel, the sarcomeres were clearly visible, and only a few filaments were broken. Additionally, $\mathrm{Z}$ lines were present, the intercalated disks were clearly visible, nuclear material was evenly distributed, and there was no nuclear cleavage or apparent condensation of chromatin. In the RI-PostC + GF109203X group, there were severely edematous myocardial cells showing membrane shrinkage and disappearance and mitochondrial swelling with some breakage of cristae and vacuolation. Some mitochondrial matrices were dense with osmiophilic particles, and the ridges were disordered and difficult to distinguish. Additionally, the outer membranes were broken, the glycogen content was decreased, the myofibrils were relaxed and markedly stretched, the $\mathrm{Z}$ lines were distorted, the myofilaments were transverse, torn, or dissolved, and some myofibrils were broken into pieces that dissolved and formed large tumors in the muscle tissue. Lastly, the nuclei were condensed, apoptotic bodies were visible, and interstitial edema was evident. These results are shown in Figure 2(a).

3.4. Apoptosis. The TUNEL method was used to compare the degree of apoptosis between experimental groups. Representative images showing regions of apoptosis (brown nuclear granules) are presented in Figure 2(b). The AI was not significantly different between the IR and RI-PostC + GF109203X groups $(P>0.05)$ but was significantly lower in the RI-PostC group than in the IR group or RI-PostC + GF109203X group (both $P<0.05$; Figure 2(c)).

3.5. Expression of Bcl-2 and Bax Proteins in Myocardial Cells. Compared to the IR and RI-PostC + GF109203X groups, the RI-PostC group showed significantly increased expression of $\mathrm{Bcl}-2$ protein and significantly decreased expression of Bax protein $(P<0.05)$. However, there were no significant differences in Bcl-2 protein expression or Bax protein expression between the IR group and the RI-PostC + GF109203X group $(P>0.05)$. The results are shown in Figure 3.

3.6. Hemodynamic Data. Heart rate before ischemia, after $5 \mathrm{~min}$ of ischemia, and after $1 \mathrm{~h}$ of ischemia did not differ significantly between the 3 groups $(P>0.05)$. Heart rate values after $3 \mathrm{~h}$ of reperfusion and after $6 \mathrm{~h}$ of reperfusion were significantly higher in the RI-PostC group than in the IR group and RI-PostC + GF109203X group $(P<0.05)$ but were similar between the IR and RI-PostC + GF109203X groups $(P>0.05)$. The data are summarized in Table 1 and Figure S2.

MAP before ischemia, after 5 min of ischemia, and after $1 \mathrm{~h}$ of ischemia also did not differ significantly between the 3 groups $(P>0.05)$. MAP values after $3 \mathrm{~h}$ of reperfusion and after $6 \mathrm{~h}$ of reperfusion were significantly higher in the RIPostC group than in the IR group and RI-PostC + GF109203X group $(P<0.05)$ but did not differ significantly between the IR and RI-PostC + GF109203X groups $(P>0.05)$. The results are summarized in Table 2 and plotted in Figure S3.

\section{Discussion}

Although the phenomenon of ischemic postconditioning is widely accepted, its precise mechanisms, especially the intracellular signaling pathways involved, remain unclear. Researchers have carried out a considerable number of studies on ischemic postconditioning and it has become evident that this phenomenon is a cardiac self-protection mechanism 

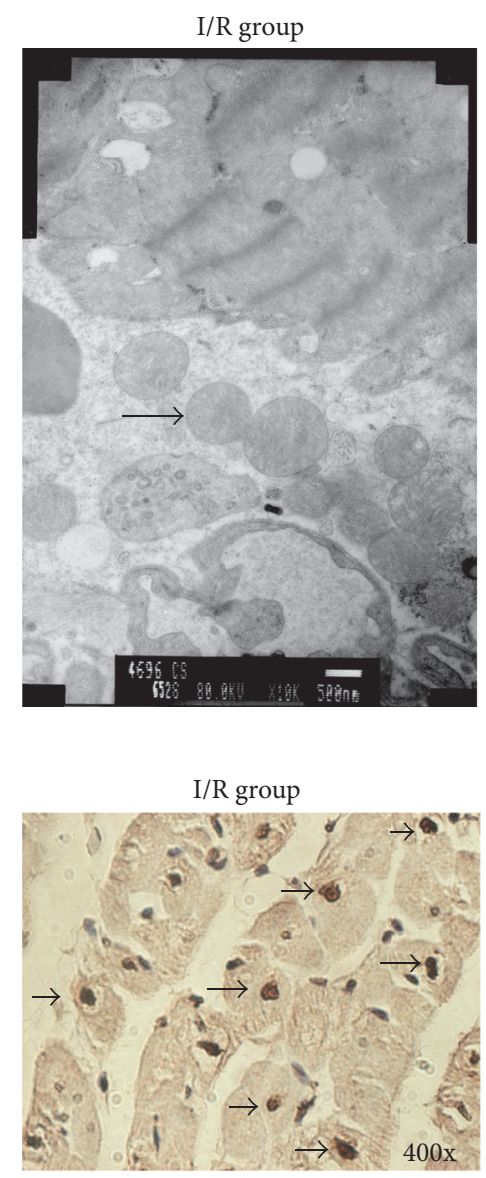

RI-PostC group

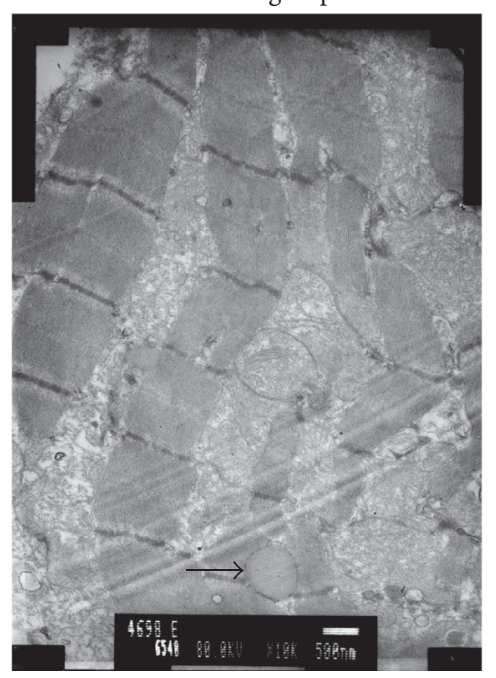

(a)

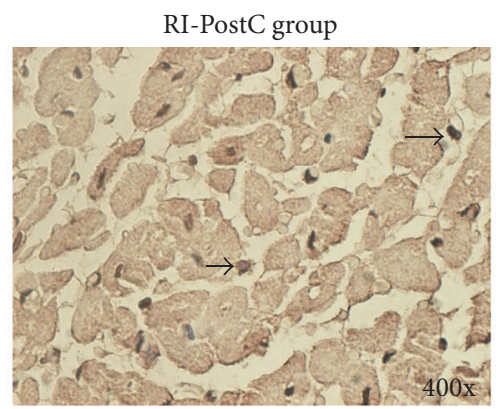

RI-PostC + GF109203X group

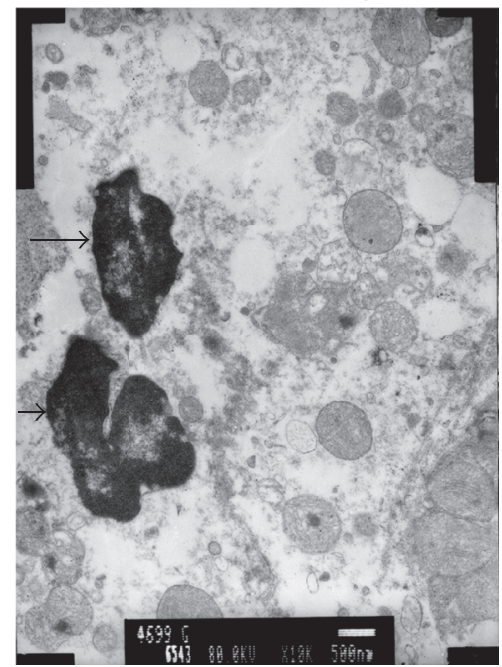

RI-PostC + GF109203X group

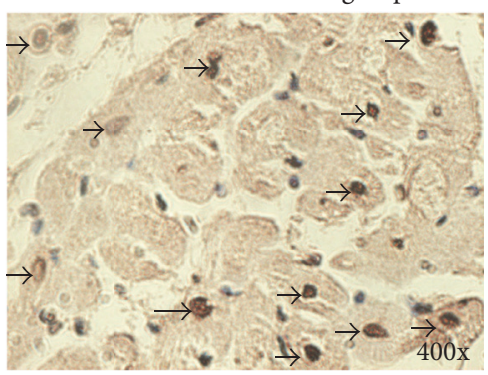

(b)

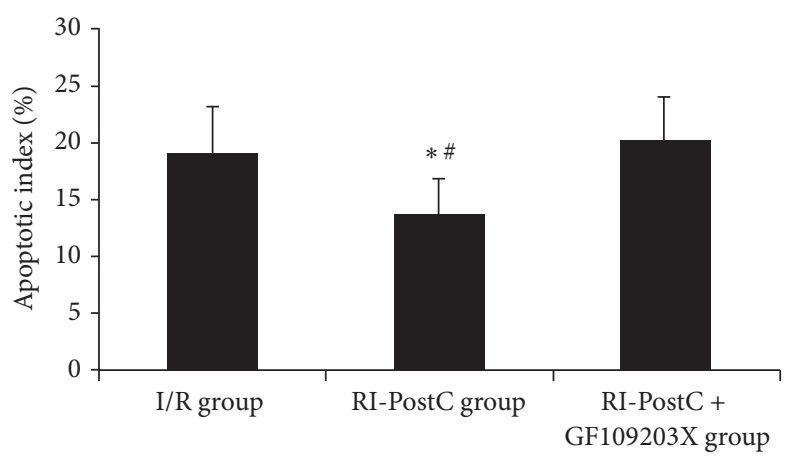

(c)

FIGURE 2: Comparison of cardiac ultrastructural changes and apoptosis between experimental groups. The IR group underwent 60 min of left anterior descending coronary artery occlusion (LADO) and $6 \mathrm{~h}$ of reperfusion only. The RI-PostC group underwent 3 cycles of left renal artery occlusion for 30 seconds and release for 30 seconds before reperfusion. The RI-PostC + GF109203X group received 0.05 mg/kg GF109203X (protein kinase C inhibitor) intravenously for $10 \mathrm{~min}$ followed by RI-PostC. There were 12 rabbits in each group. (a) Electron microscopy observations. IR group: many mitochondria had extruded from the cells (arrows). RI-PostC group: the mitochondria were slightly swollen, and there was vacuolar degeneration (arrow) with partial disappearance of the ridges. RI-PostC + GF109203X group: extensive ultrastructural abnormalities were present, including 2 apoptotic bodies (arrows). (b) TUNEL assay for myocardial cell apoptosis (arrows point to TUNEL positive cells). (c) Comparison of AI between groups, calculated from experiments such as those shown in (b) $\left(n=12\right.$ per group). ${ }^{*} P<0.05$ compared with the IR group; ${ }^{*} P<0.05$ compared with the RI-PostC + GF109203X group. 


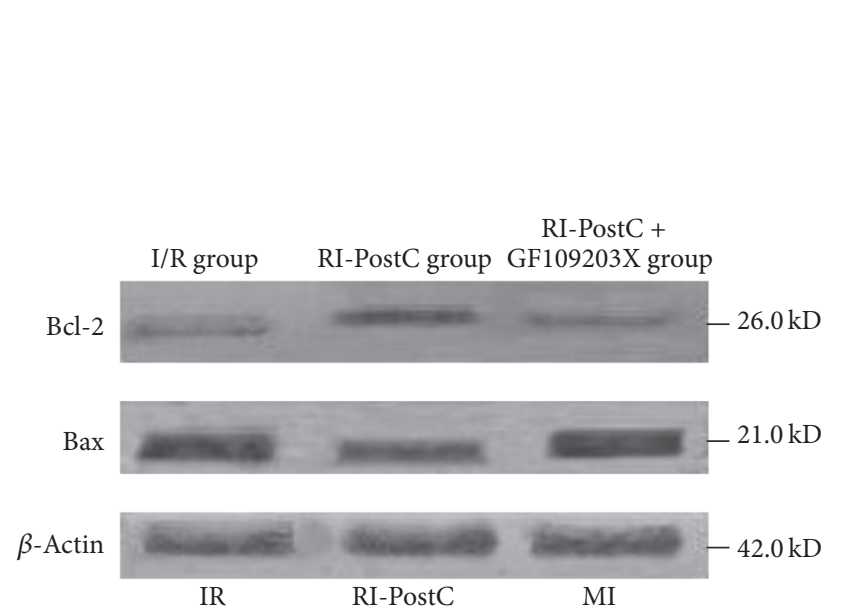

(a)

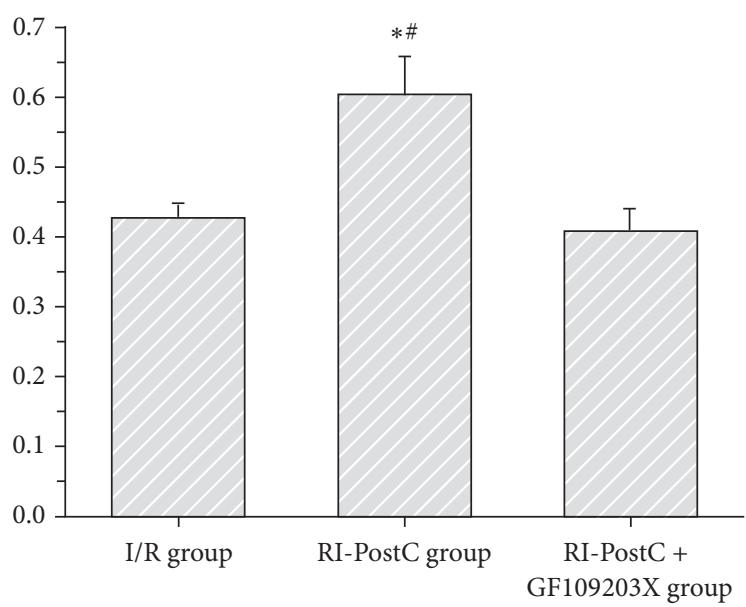

(b)

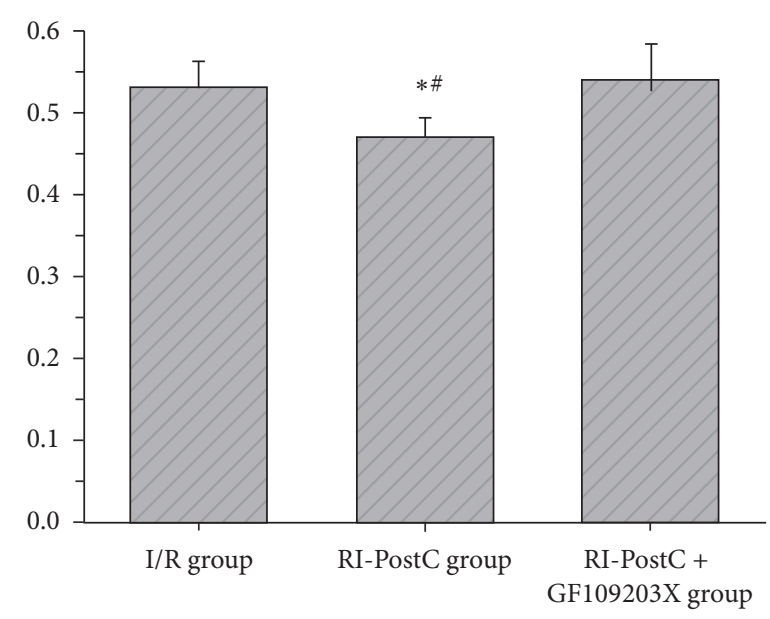

(c)

FIgURE 3: Myocardial Bcl-2 and Bax protein expression levels. The IR group underwent 60 min of left anterior descending coronary artery occlusion (LADO) and $6 \mathrm{~h}$ of reperfusion only. The RI-PostC group underwent 3 cycles of left renal artery occlusion for 30 seconds and release for 30 seconds before reperfusion. The RI-PostC + GF109203X group received $0.05 \mathrm{mg} / \mathrm{kg}$ GF109203X (protein kinase C inhibitor) intravenously for $10 \mathrm{~min}$ followed by RI-PostC. There were 12 rabbits in each group. (a) Representative Western blot image showing the expression of $\mathrm{Bcl}-2$, Bax, and $\beta$-actin in the 3 groups. (b) Expression of Bcl- 2 relative to that of $\beta$-actin $(n=12)$. Bcl- 2 protein expression was higher in the RI-PostC group than in the other 2 groups $(P<0.05)$. (c) Bax protein expression relative to that of $\beta$-actin $(n=12)$. Bax protein expression in the RI-PostC group was lower than that in the other 2 groups $(P<0.05) .{ }^{*} P<0.05$ compared with the IR group; ${ }^{\#} P<0.05$ compared with the RI-PostC + GF109203X group.

that triggers the heart to release endogenous active compounds during the early onset of ischemia, which in turn regulate cardiac function through intracellular signal transduction systems $[22,26]$. Accordingly, ischemic postconditioning increases the tolerance of the myocardium to longer ischemic periods and provides protective benefits before and after such events. Currently, cellular signal transduction in ischemic postconditioning is believed to involve three basic component elements [27]: triggering materials (endogenous active materials), mesomeric materials (protein kinases), and effector substances (ion channels and protective proteins). Our current understanding of the mechanism of ischemic postconditioning is that repeated ischemia-reperfusion could release numerous endogenous substances such as adenosine and bradykinin $[28,29]$. These substances could affect their corresponding receptors to induce the activation of PKC and other kinases. So postconditioning involves pathways including adenosine receptor activation and PKC signaling [20]; dopamine receptor activation induced translocation of $\mathrm{PKC} \varepsilon$ [30] and PKC $\varepsilon$ interacting with calcium sensing receptor to protect cardiomyocytes from apoptosis [31]. Eventually, these enzymes could alter the function of mitochondrial ATPsensitive channels and protect the heart [32,33]. The opening of the mitochondrial permeability transition pore ( $\mathrm{mPTP})$ is the crucial event that may cause either apoptosis or necrosis of reperfused myocardium [34-37].

PKC is an important component of the myocardial cell monophosphoinositide signal transduction system and its role in IPC has been previously described [38-40]. Recently, new findings have indicated that ischemic postconditioning 
also affects the reconstitution of myocardial cellular membranes and reduces or inhibits myocardial cell apoptosis, thereby protecting the heart.

Remote IPC involves brief nonlethal ischemia to a remote organ or tissue with the intention of reducing perioperative myocardial injury in patients undergoing coronary artery bypass grafting surgery [41]. Remote IPC can be performed simply, by inflating and deflating a standard blood-pressure cuff placed on the upper arm or thigh. However, some clinical trials suggest that remote IPC does not improve outcomes after cardiac surgery [42, 43]. Meta-analysis suggests that overall mortality is not decreased with remote IPC, but it was associated with less myocardial infarction and acute renal failure and shorter hospitalization time in patients undergoing cardiac or vascular surgery [44]. Since the timing of a cardiac ischemic event cannot be predicted in advance, ischemic postconditioning is potentially better suited to clinical applications than IPC. It has been shown that repeated transitory opening and closing of the coronary artery before continuous reperfusion of the coronary artery (i.e., ischemic postconditioning) offered relief of ischemicreperfusion damage and delivered notable protection. Some studies $[45,46]$ have suggested that ischemic postconditioning could affect the expression of substances such as cellular membrane connexin-43 and nitric oxide (NO).

Changes in myocardial ultrastructure are the most intuitive indicators of cellular damage. Myocardial ischemia lasting for 30-40 min can induce damage to myocardial cells. We detected many neutrophils and red blood cells with normal myocardial cells using light microscopy. Mitochondria are not only vital to maintain somatic cellular oxygen and energy production, but, more importantly, to inhibit the destructive actions of oxygen free radicals. Therefore, the mitochondrion is a key organelle to distinguish reversible from irreversible cellular changes, as it is a sensitive indicator of myocardial injury. Damage caused by ischemia includes diffuse mitochondrial swelling, membrane rupture, cristae dissolution or disappearance, and the appearance of osmiophilic particles. This study found that RI-PostC could ameliorate the ultrastructural changes of myocardial cells caused by ischemia and enhance myocardial protection.

Apoptosis describes the spontaneous death of normal body cells induced by physiological or pathological stimuli. Ischemia-reperfusion injury can induce apoptosis, which is an important part of the pathogenesis. Bcl-2 is an apoptosissuppressor gene and its overexpression can block apoptosis induced by various stimuli. The Bax gene promotes apoptosis and is mainly expressed in the mitochondrial membrane and endoplasmic reticulum. Bax and Bcl-2 share a high homology and can form heterodimers, which can inhibit the activity of $\mathrm{Bcl}-2$ and induce apoptosis. Therefore, the $\mathrm{Bcl}-2 / \mathrm{Bax}$ protein ratio may determine the level of cell apoptosis or survival following apoptotic injury [47]. In this study, Bcl-2 and Bax protein expression were detected by Western blot analysis and the results showed that, compared with the other groups, Bcl2 protein expression was increased in the RI-PostC group while Bax protein expression was significantly reduced. These results further show that RI-PostC had a prominent influence on the expression of apoptosis-related genes induced by myocardial ischemia and reperfusion, namely, increased Bcl2 expression and decreased Bax expression, thereby exerting a protective effect on myocardial tissue.

We found that a PKC inhibitor (GF109203X) could block the protective effects on the heart produced by RI-PostC. Therefore, we propose that the cardioprotection offered by RI-PostC may have been related to the ability of PKC to activate a reperfusion injury salvage enzyme pathway. This process has been shown to produce effective phosphorylation of mitochondrial ATP-sensitive channels and induce myocardial preservation [48-50]. However, the specific mechanisms need to be studied further.

The present study was not designed to investigate the mechanisms underlying the beneficial effects of RI-PostC on cardiac ischemia-reperfusion injury, and the underlying pathways have yet to be established. However, based on the information currently available regarding the mechanisms of preconditioning and postconditioning [51-55], we speculate that RI-PostC resulted in the renal release of various mediators, possibly including NO and adenosine, that acted on the heart to limit the damage associated with reperfusion. The cardiac signaling mechanisms activated by these mediators likely included the PKC pathway, reperfusion injury salvage kinase (RISK) pathway (PI3K/Akt and ERK signaling with downstream inhibition of GSK-3 $\beta$ ), guanylate cyclase/cGMP pathway, and JAK/STAT3 pathway [51-55]. In turn, these pathways would act to reduce cellular and mitochondrial calcium overload and inhibit necrosis and apoptosis via alterations in $\mathrm{Bcl}-2 / \mathrm{Bax}$ expression, opening of the mitochondrial ATP channel, and inhibition of mPTP opening. However, additional research will be required to elucidate the precise mechanisms.

This study has some limitations. There are known differences in the response to ischemia between the different genders $[56,57]$. However, as this issue is a complex one we did not address this in this study. To try and avoid bias we included the same ratio of male/female rabbits in each group, but gender difference should be considered in the future. We also did not have a group of rabbits that were treated with the GF109203X kinase inhibitor alone. Therefore, we do not know whether the inhibitor had any effect on the rabbits without RI-PostC. We selected TUNEL and Bcl2/Bax Western blot analysis to comprehensively demonstrate the degree of apoptosis, but caspase 3 and other apoptosis-related proteins were not detected.

\section{Conclusions}

RI-PostC can protect the heart from ischemia-reperfusion injury through a mechanism involving PKC. It has been previously demonstrated that remote organ ischemic postconditioning has protective effects on myocardial tissue; however, studies of ischemic postconditioning are scarce and clinical reports are particularly rare [58]. In addition, this study is limited to animal experiments, so there is great potential for future research to identify potentially beneficial effects of ischemic postconditioning in other organ systems against myocardial reperfusion injury, particularly in patients undergoing cardiac revascularization. 


\section{Competing Interests}

The authors have no financial disclosures or conflicts to declare.

\section{References}

[1] A. Aimo, C. Borrelli, A. Giannoni et al., "Cardioprotection by remote ischemic conditioning: mechanisms and clinical evidences," World Journal of Cardiology, vol. 7, no. 10, pp. 621632, 2015.

[2] M. Ovize and E. Bonnefoy, "Giving the ischaemic heart a shot in the arm," The Lancet, vol. 375, no. 9716, pp. 699-700, 2010.

[3] C. E. Murry, R. B. Jennings, and K. A. Reimer, "Preconditioning with ischemia: a delay of lethal cell injury in ischemic myocardium," Circulation, vol. 74, no. 5, pp. 1124-1136, 1986.

[4] J. Vinten-Johansen, Z.-Q. Zhao, A. J. Zatta, H. Kin, M. E. Halkos, and F. Kerendi, "Postconditioning: a new link in nature's armor against myocardial ischemia-reperfusion injury," Basic Research in Cardiology, vol. 100, no. 4, pp. 295-310, 2005.

[5] Z. Q. Zhao, J. S. Corvera, M. E. Halkos et al., "Inhibition of myocardial injury by ischemic postconditioning during reperfusion: comparison with ischemic preconditioning," American Journal of Physiology-Heart and Circulatory Physiology, vol. 285, pp. H579-H588, 2003.

[6] D. M. Hong, Y. Jeon, C.-S. Lee et al., "Effects of remote ischemic preconditioning with postconditioning in patients undergoing off-pump coronary artery bypass surgery-Randomized controlled trial," Circulation Journal, vol. 76, no. 4, pp. 884-890, 2012.

[7] X. Weng, L. Wang, H. Chen, X. Liu, T. Qiu, and Z. Chen, "Ischemic postconditioning inhibits apoptosis in an in vitro proximal tubular cell model," Molecular Medicine Reports, vol. 12, no. 1, pp. 99-104, 2015.

[8] E. V. Shliakhto, M. M. Galagudza, A. V. Syrenskiŭ, and V. A. Tsyrlin, "[Ischemic postconditioning of the myocardium: a new method of heart protection against reperfusion damage]," Terapevticheskii Arkhiv, vol. 77, no. 5, pp. 77-80, 2005.

[9] Y. C. Xu, F. S. Xue, X. Liao et al., "Combined morphine and limb remote ischaemia postconditioning may produce an enhanced cardioprotection," Medical Hypotheses, vol. 73, no. 3, pp. 302305, 2009.

[10] S. P. Loukogeorgakis, R. Williams, A. T. Panagiotidou et al., "Transient limb ischemia induces remote preconditioning and remote postconditioning in humans by a KATP channeldependent mechanism," Circulation, vol. 116, no. 12, pp. 13861395, 2007.

[11] G. Crimi, S. Pica, C. Raineri et al., "Remote ischemic postconditioning of the lower limb during primary percutaneous coronary intervention safely reduces enzymatic infarct size in anterior myocardial infarction: a randomized controlled trial," JACC: Cardiovascular Interventions, vol. 6, no. 10, pp. 1055-1063, 2013.

[12] R. J. Schott and W. Schaper, "Ischemic preconditioning and myocardial stunning: related consequences of brief coronary occlusion and reperfusion," Advances in Cardiology, vol. 37, pp. 32-41, 1990.

[13] G. C. Li, J. A. Vasquez, K. P. Gallagher, and B. R. Lucchesi, "Myocardial protection with preconditioning," Circulation, vol. 82, no. 2, pp. 609-619, 1990.
[14] J. Vinten-Johansen and W. Shi, "The science and clinical translation of remote postconditioning," Journal of Cardiovascular Medicine, vol. 14, no. 3, pp. 206-213, 2013.

[15] H. Zhong, Z. Gao, M. Chen et al., "Cardioprotective effect of remote ischemic postconditioning on children undergoing cardiac surgery: a randomized controlled trial," Paediatric Anaesthesia, vol. 23, no. 8, pp. 726-733, 2013.

[16] M. R. Schmidt, A. D. Sloth, J. Johnsen, and H. E. Bøtker, "Remote ischemic conditioning: the cardiologist's perspective," Journal of Cardiovascular Medicine, vol. 13, no. 11, pp. 667-674, 2012.

[17] L. Lai, X. J. Zhang, X. Y. Zhang et al., "Lazaroid U83836E protects the heart against ischemia reperfusion injury via inhibition of oxidative stress and activation of PKC," Molecular Medicine Reports, vol. 13, no. 5, pp. 3993-4000, 2016.

[18] Q. Miao, S. Wang, S. Miao, J. Wang, Y. Xie, and Q. Yang, "Cardioprotective effect of polydatin against ischemia/reperfusion injury: roles of protein kinase C and mito KATP activation," Phytomedicine, vol. 19, no. 1, pp. 8-12, 2011.

[19] T. Sasaki, T. Shishido, S. Kadowaki et al., "Diacylglycerol kinase $\alpha$ exacerbates cardiac injury after ischemia/reperfusion," Heart and Vessels, vol. 29, no. 1, pp. 110-118, 2014.

[20] S. M. Eldaif, J. A. Deneve, N.-P. Wang et al., "Attenuation of renal ischemia-reperfusion injury by postconditioning involves adenosine receptor and protein kinase $\mathrm{C}$ activation," Transplant International, vol. 23, no. 2, pp. 217-226, 2010.

[21] A. Lazou, E. K. Iliodromitis, D. Cieslak et al., "Ischemic but not mechanical preconditioning attenuates ischemia/reperfusion induced myocardial apoptosis in anaesthetized rabbits: the role of Bcl-2 family proteins and ERK1/2," Apoptosis, vol. 11, no. 12, pp. 2195-2204, 2006.

[22] F. Kerendi, H. Kin, M. E. Halkos et al., "Remote postconditioning: brief renal ischemia and reperfusion applied before coronary artery reperfusion reduces myocardial infarct size via endogenous activation of adenosine receptors," Basic Research in Cardiology, vol. 100, no. 5, pp. 404-412, 2005.

[23] M. Lu, F. Tang, J. Zhang et al., "Astragaloside IV attenuates injury caused by myocardial ischemia/reperfusion in rats via regulation of toll-like receptor $4 /$ nuclear factor- $\kappa \mathrm{b}$ signaling pathway," Phytotherapy Research, vol. 29, no. 4, pp. 599-606, 2015.

[24] L. Barile, V. Lionetti, E. Cervio et al., "Extracellular vesicles fromhuman cardiac progenitor cells inhibit cardiomyocyte apoptosis and improve cardiac function aftermyocardial infarction," Cardiovascular Research, vol. 103, no. 4, pp. 530-541, 2014.

[25] H.-S. Ding, J. Yang, P. Chen et al., "The HMGB1-TLR4 axis contributes to myocardial ischemia/reperfusion injury via regulation of cardiomyocyte apoptosis," Gene, vol. 527, no. 1, pp. 389-393, 2013.

[26] X.-G. Chen, B.-Y. Wu, J.-K. Wang, and T. Bai, "Mechanism of the protective effects of noninvasive limbs preconditioning on myocardial ischemia-reperfusion injury," Chinese Medical Journal, vol. 118, no. 20, pp. 1723-1727, 2005.

[27] M. Ovize, G. F. Baxter, F. Di Lisa et al., "Postconditioning and protection from reperfusion injury: where do we stand: position Paper from the Working Group of Cellular Biology of the Heart of the European Society of Cardiology," Cardiovascular Research, vol. 87, no. 3, pp. 406-423, 2010.

[28] G. S. Liu, J. Thornton, D. M. Van Winkle, A. W. H. Stanley, R. A. Olsson, and J. M. Downey, "Protection against infarction afforded by preconditioning is mediated by Al adenosine receptors in rabbit heart," Circulation, vol. 84, no. 1, pp. 350-356, 1991. 
[29] S. Philipp, X.-M. Yang, L. Cui, A. M. Davis, J. M. Downey, and M. V. Cohen, "Postconditioning protects rabbit hearts through a protein kinase C-adenosine $\mathrm{A}_{2 b}$ receptor cascade," Cardiovascular Research, vol. 70, no. 2, pp. 308-314, 2006.

[30] J. Gao, J. Guo, H. Li et al., "Involvement of dopamine D2 receptors activation in ischemic post-conditioning-induced cardioprotection through promoting PKC- $\varepsilon$ particulate translocation in isolated rat hearts," Molecular and Cellular Biochemistry, vol. 379, no. 1, pp. 267-276, 2013.

[31] S. Dong, Z. Teng, F.-H. Lu et al., "Post-conditioning protects cardiomyocytes from apoptosis via PKC $\varepsilon$-interacting with calcium-sensing receptors to inhibit endo(sarco)plasmic reticulum-mitochondria crosstalk," Molecular and Cellular Biochemistry, vol. 341, no. 1-2, pp. 195-206, 2010.

[32] N. Maulik, M. Watanabe, Y.-L. Zu et al., "Ischemic preconditioning triggers the activation of MAP kinases and MAPKAP kinase 2 in rat hearts," FEBS Letters, vol. 396, no. 2-3, pp. 233237, 1996.

[33] S. S. Prasad, M. Russell, and M. Nowakowska, "Neuroprotection induced in vitro by ischemic preconditioning and postconditioning: modulation of apoptosis and PI3K-Akt pathways," Journal of Molecular Neuroscience, vol. 43, no. 3, pp. 428-442, 2011.

[34] L. Argaud, O. Gateau-Roesch, O. Raisky, J. Loufouat, D. Robert, and M. Ovize, "Postconditioning inhibits mitochondrial permeability transition," Circulation, vol. 111, no. 2, pp. 194-197, 2005.

[35] L. Gomez, M. Paillard, H. Thibault, G. Derumeaux, and M. Ovize, "Inhibition of GSK $3 \beta$ by postconditioning is required to prevent opening of the mitochondrial permeability transition pore during reperfusion," Circulation, vol. 117, no. 21, pp. 27612768, 2008.

[36] T. Shahzad, S. A. Kasseckert, W. Iraqi et al., "Mechanisms involved in postconditioning protection of cardiomyocytes against acute reperfusion injury," Journal of Molecular and Cellular Cardiology, vol. 58, no. 1, pp. 209-216, 2013.

[37] S.-G. Ong, W. H. Lee, L. Theodorou et al., "HIF-1 reduces ischaemia-reperfusion injury in the heart by targeting the mitochondrial permeability transition pore," Cardiovascular Research, vol. 104, no. 1, pp. 24-36, 2014.

[38] S. Murphy and W. H. Frishman, "Protein kinase C in cardiac disease and as a potential therapeutic target," Cardiology in Review, vol. 13, no. 1, pp. 3-12, 2005.

[39] C. Penna, R. Rastaldo, D. Mancardi et al., "Post-conditioning induced cardioprotection requires signaling through a redoxsensitive mechanism, mitochondrial ATP-sensitive K+ channel and protein kinase C activation," Basic Research in Cardiology, vol. 101, no. 2, pp. 180-189, 2006.

[40] J.-C. Bopassa, R. Ferrera, O. Gateau-Roesch, E. CoutureLepetit, and M. Ovize, "PI 3-kinase regulates the mitochondrial transition pore in controlled reperfusion and postconditioning," Cardiovascular Research, vol. 69, no. 1, pp. 178-185, 2006.

[41] M. Thielmann, E. Kottenberg, K. Boengler et al., "Remote ischemic preconditioning reduces myocardial injury after coronary artery bypass surgery with crystalloid cardioplegic arrest," Basic Research in Cardiology, vol. 105, no. 5, pp. 657-664, 2010.

[42] D. J. Hausenloy, L. Candilio, R. Evans et al., "Remote ischemic preconditioning and outcomes of cardiac surgery," New England Journal of Medicine, vol. 373, no. 15, pp. 1408-1417, 2015.

[43] P. Meybohm, B. Bein, O. Brosteanu et al., "A multicenter trial of remote ischemic preconditioning for heart surgery," New England Journal of Medicine, vol. 373, no. 15, pp. 1397-1407, 2015.
[44] P. Sardar, S. Chatterjee, A. Kundu et al., "Remote ischemic preconditioning in patients undergoing cardiovascular surgery: evidence from a meta-analysis of randomized controlled trials," International Journal of Cardiology, vol. 221, pp. 34-41, 2016.

[45] H. He, N. Li, Z. Zhao, F. Han, X. Wang, and Y. Zeng, "Ischemic postconditioning improves the expression of cellular membrane connexin 43 and attenuates the reperfusion injury in rat acute myocardial infarction," Biomedical Reports, vol. 3, no. 5, pp. 668-674, 2015.

[46] S. Jeddi, J. Zaman, and A. Ghasemi, "Effects of ischemic postconditioning on the hemodynamic parameters and heart nitric oxide levels of hypothyroid rats," Arquivos Brasileiros de Cardiologia, vol. 104, no. 2, pp. 136-143, 2014.

[47] S. Love, "Apoptosis and brain ischaemia," Progress in NeuroPsychopharmacology and Biological Psychiatry, vol. 27, no. 2, pp. 267-282, 2003.

[48] L. M. Schwartz and C. J. Lagranha, "Ischemic postconditioning during reperfusion activates Akt and ERK without protecting against lethal myocardial ischemia-reperfusion injury in pigs," American Journal of Physiology-Heart and Circulatory Physiology, vol. 290, no. 3, pp. H1011-H1018, 2006.

[49] C. E. Darling, K. Jiang, M. Maynard, P. Whittaker, J. VintenJohansen, and K. Przyklenk, "Postconditioning via stuttering reperfusion limits myocardial infarct size in rabbit hearts: role of ERK1/2," American Journal of Physiology-Heart and Circulatory Physiology, vol. 289, no. 4, pp. H1618-H1626, 2005.

[50] Y. B. Lishmanov and L. N. Maslov, "Ischemic postconditioning of the heart. Receptor mechanisms and possibility of clinical use," Kardiologiya, vol. 50, no. 6, pp. 68-74, 2010.

[51] C. Kierulf-Lassen, G. J. Nieuwenhuijs-Moeke, N. V. Krogstrup, M. Oltean, B. Jespersen, and F. J. M. F. Dor, "Molecular mechanisms of renal ischemic conditioning strategies," European Surgical Research, vol. 55, no. 3, pp. 151-183, 2015.

[52] H. Moradi and P. H. Wang, "Renoprotective mechanisms of ischemic postconditioning in ischemia-reperfusion injury: improved mitochondrial function and integrity," Nephrology Dialysis Transplantation, vol. 28, no. 11, pp. 2667-2669, 2013.

[53] J. S. Bice and G. F. Baxter, "Postconditioning signalling in the heart: mechanisms and translatability," British Journal of Pharmacology, vol. 172, no. 8, pp. 1933-1946, 2015.

[54] Q. Iqbal and S. Garcia, "Myocardial protection through preand post-conditioning: a review of mechanisms, clinical trials and future directions," Journal of Cardiovascular Diseases \& Diagnosis, vol. 1, article no. 115, 2013.

[55] S.-B. Zhu, Y. Liu, Y. Zhu et al., "Remote preconditioning, perconditioning, and postconditioning: a comparative study of their cardioprotective properties in rat models," Clinics, vol. 68, no. 2, pp. 263-268, 2013.

[56] W. T. Ip, A. McAlindon, S. E. Miller et al., "Dietary omega6 fatty acid replacement selectively impairs cardiac functional recovery after ischemia in female (but not male) rats," American Journal of Physiology-Heart and Circulatory Physiology, vol. 311, no. 3, pp. H768-H780, 2016.

[57] C. L. Blenck, P. A. Harvey, J. F. Reckelhoff, and L. A. Leinwand, "The importance of biological sex and estrogen in rodent models of cardiovascular health and disease," Circulation Research, vol. 118, no. 8, pp. 1294-1312, 2016.

[58] J. Xiong, X. Liao, F.-S. Xue, Y.-J. Yuan, Q. Wang, and J.-H. Liu, "Remote ischemia conditioning-an endogenous cardioprotective strategy from outside the heart," Chinese Medical Journal, vol. 124, no. 14, pp. 2209-2215, 2011. 


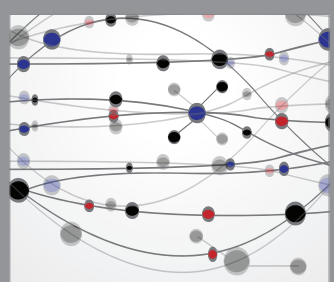

The Scientific World Journal
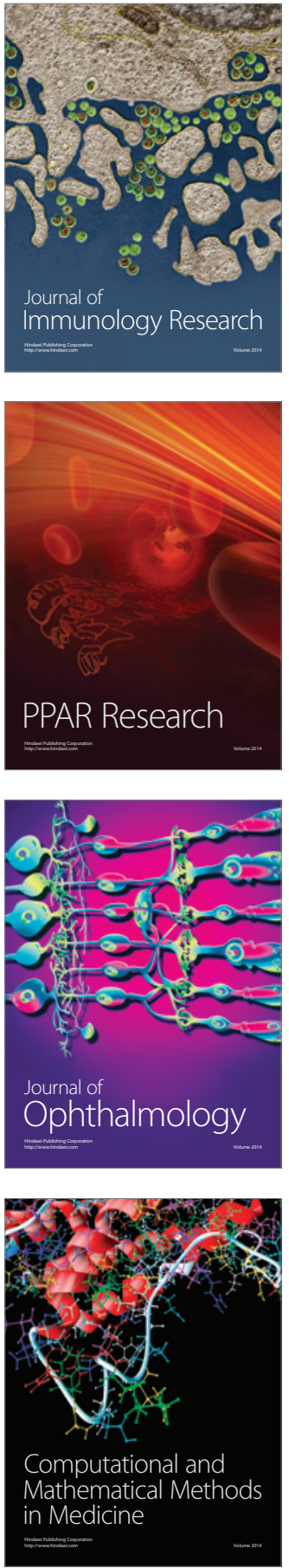

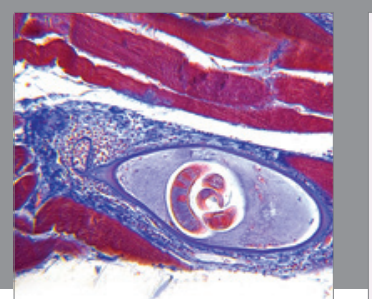

Gastroenterology Research and Practice

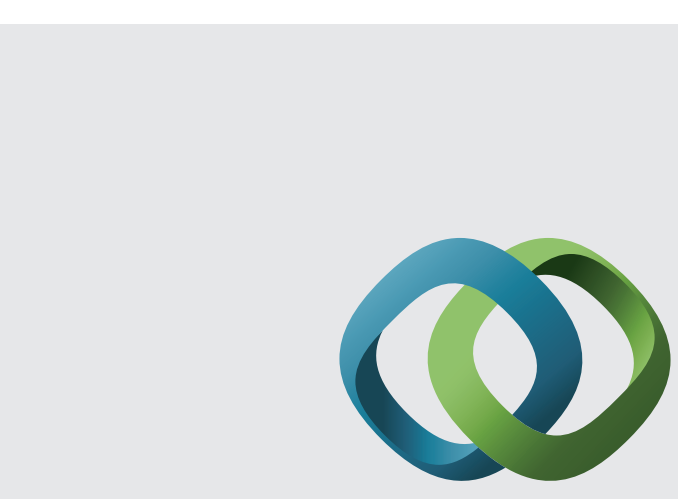

\section{Hindawi}

Submit your manuscripts at

http://www.hindawi.com
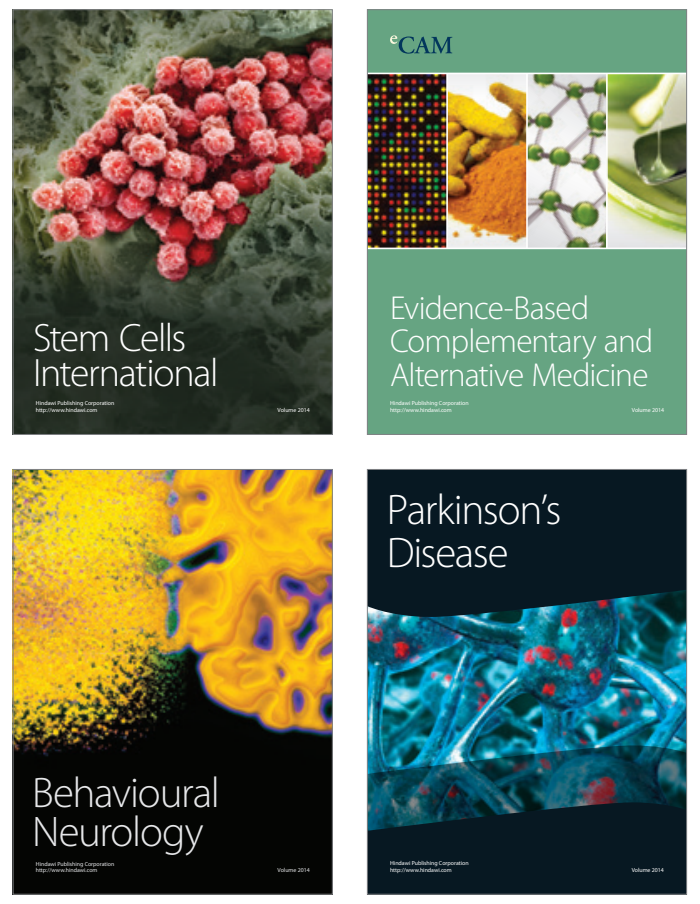
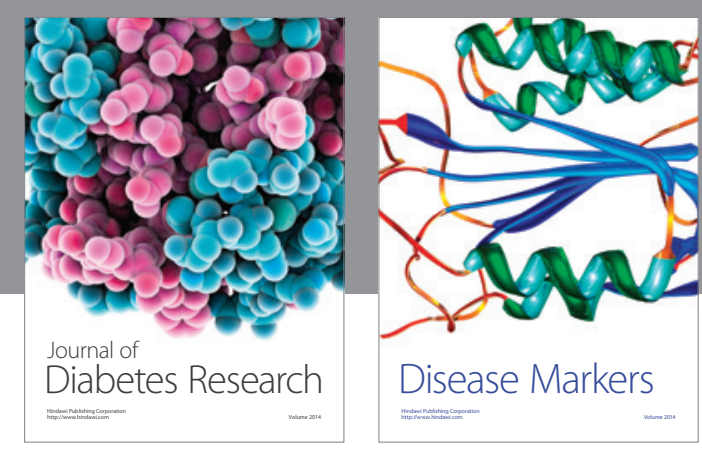

Disease Markers
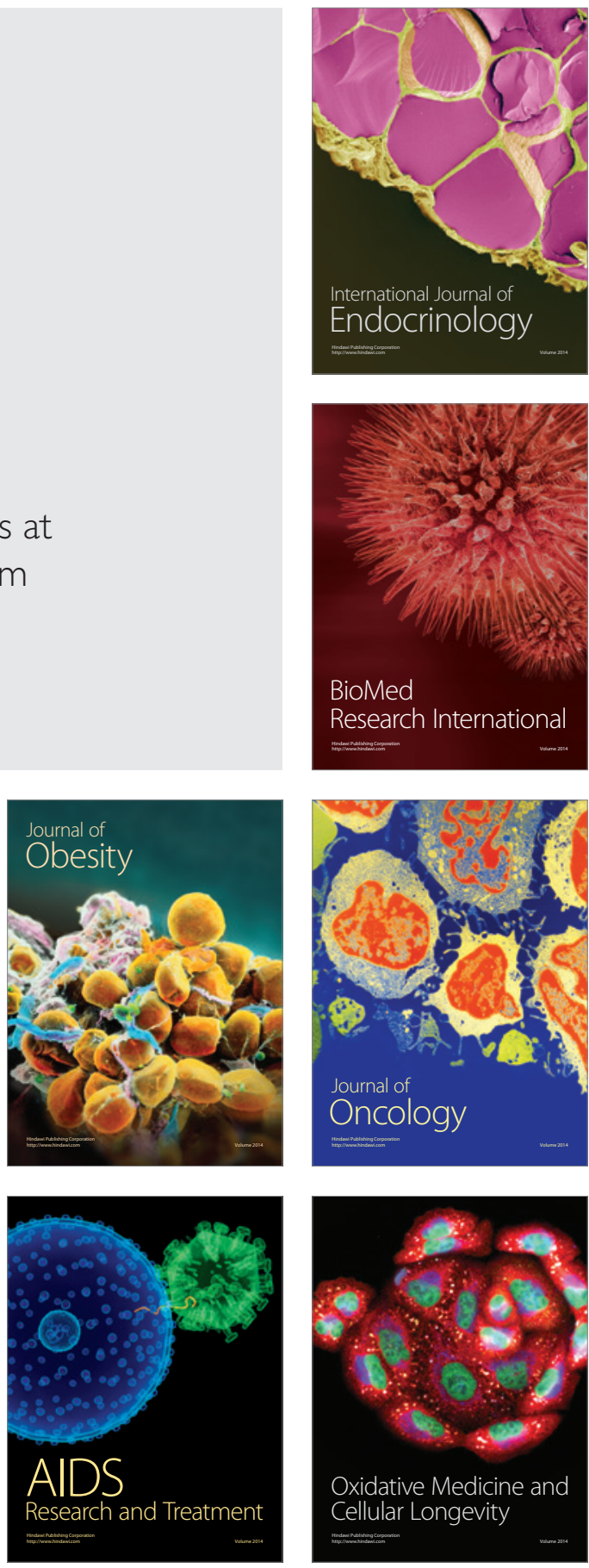